\title{
Treatment of Cushing disease: overview and recent findings
}

\author{
This article was published in the following Dove Press journal: \\ Therapeutics and Clinical Risk Management \\ II October 2010 \\ Number of times this article has been viewed
}

\author{
Tatiana Mancini' \\ Teresa Porcelli² \\ Andrea Giustina ${ }^{2}$ \\ 'Department of Internal Medicine \\ and Medical Specialties, San Marino \\ Hospital, San Marino, Republic of \\ San Marino, ${ }^{2}$ Department of Medical \\ and Surgical Sciences, University of \\ Brescia, Brescia, Italy
}

\begin{abstract}
Endogenous Cushing syndrome is an endocrine disease caused by excessive secretion of adrenocorticotropin hormone in approximately $80 \%$ of cases, usually by a pituitary corticotroph adenoma (Cushing disease [CD]). It is a heterogeneous disorder requiring a multidisciplinary and individualized approach to patient management. The goals of treatment of $\mathrm{CD}$ include the reversal of clinical features, the normalization of biochemical changes with minimal morbidity, and long-term control without recurrence. Generally, the treatment of choice is the surgical removal of the pituitary tumor by transsphenoidal approach, performed by an experienced surgeon. Considering the high recurrence rate, other treatments should be considered. Second-line treatments include more radical surgery, radiation therapy, medical therapy, and bilateral adrenalectomy. Drug treatment has been targeted at the hypothalamic or pituitary level, at the adrenal gland, and also at the glucocorticoid receptor level. Frequently, medical therapy is performed before surgery to reduce the complications of the procedure, reducing the effects of severe hypercortisolism. Commonly, in patients in whom surgery has failed, medical management is often essential to reduce or normalize the hypercortisolemia, and should be attempted before bilateral adrenalectomy is considered. Medical therapy can be also useful in patients with $\mathrm{CD}$ while waiting for pituitary radiotherapy to take effect, which can take up to 10 years or more. So far, results of medical treatment of CD have not been particularly relevant; however, newer tools promise to change this scenario. The aim of this review is to analyze the results and experiences with old and new medical treatments of $\mathrm{CD}$ and to reevaluate medical therapies for complications of $\mathrm{CD}$ and hypopituitarism in patients with cured $\mathrm{CD}$.
\end{abstract}

Keywords: ketoconazole, somatostatin analogs, dopamine agonists, rosiglitazone, Cushing disease, glucocorticoids, hypopituitarism

\section{Introduction}

Endogenous Cushing syndrome is an endocrine disease caused by excessive secretion of adrenocorticotropin hormone (ACTH) in approximately $80 \%$ of cases, usually by a pituitary corticotroph adenoma (Cushing disease [CD]), less often by an extrapituitary tumor (ectopic ACTH syndrome), and very rarely by an ectopic corticotropin-releasing hormone - secreting tumor. ACTH-independent Cushing syndrome, accounting for about $20 \%$, is due in most instances to an adrenal tumor, or more rarely, macronodular adrenal hyperplasia, primary pigmented nodular adrenal disease (either as isolated disease or as a part of Carney complex), or McCune-Albright syndrome. ${ }^{1,2}$

In $\mathrm{CD}$, elevated $\mathrm{ACTH}$ secretion results in excess adrenal gland cortisol secretion. The normal cortisol feedback mechanism of the hypothalamic-pituitary-adrenal axis is disturbed, with loss of circadian rhythm and excess cortisol production, resulting 
in hypercortisolism. Clinical features of hypercortisolism include weight gain, severe fatigue and muscle weakness, high blood pressure, depression, cognitive impairment, purplish skin striae, easy bruising, loss of libido, diabetes, hirsutism, acne, and menstrual disorders. The nonspecificity and high prevalence of clinical symptoms in patients without the disorder complicate the diagnosis of Cushing syndrome and also the differential diagnosis between the different causes of hypercortisolism. ${ }^{1}$ For this reason, efficient screening and confirmatory procedures are essential before considering therapy. On the other hand, in untreated cases, morbidity and mortality rates are significantly elevated compared with those in normal subjects especially for the high cardiovascular and osteoporotic risk. ${ }^{3-8}$

The goals of treatment of CD include the reversal of clinical features, the normalization of biochemical changes with minimal morbidity, and long-term control without recurrence. ${ }^{9}$

$\mathrm{CD}$ is caused by an $\mathrm{ACTH}$-secreting tumor in the majority of cases, and so, optimal treatment is surgical resection by selective adenomectomy. In the event of failure after initial pituitary surgery or relapse after a period of remission, the second-line therapeutic options include repeated pituitary surgery, radiotherapy, or bilateral adrenalectomy. Finally, medical therapy may have a primary or adjunctive role in some cases. This review will focus on surgical treatment of $\mathrm{CD}$, on therapies in case of persistent disease after transsphenoidal surgery (TS), and on medical management of CD.

\section{Surgical treatment of CD}

The first-line treatment of CD is the surgical removal of the pituitary tumor by transsphenoidal approach, performed by an experienced surgeon. Repeated TS may be undertaken if disease persists after initial surgery as soon as persistent disease is evident, but a delay of 4-6 weeks may be required to confirm the need for reoperation. ${ }^{9}$ The transsphenoidal microsurgery is still the most widely used technique; there are still less data available on outcome in entirely endoscopic surgery. ${ }^{9}$ However, the excellent view of the surgical field during endoscopic TS seems to provide an advantage in case of altered anatomy in repeated surgery. ${ }^{10}$

\section{Efficacy}

Remission rates in patients with microadenoma are in the range of $65 \%-90 \%$. The recurrence rates are $5 \%-10 \%$ at 5 years and $10 \%-20 \%$ at 10 years. In patients with macroadenoma, remission rates are lower $(<65 \%$ in most series), and recurrence also occurs sooner than in those with microadenoma (mean of 16 months vs 49 months). ${ }^{11,12}$
If an adenoma cannot be located in sellar exploration, total or partial hypophysectomy may be indicated, but there is consensus that it may induce remission less often than a selective tumor resection. ${ }^{9}$ The rate of success is also lower in repeated TS than that seen after the initial surgery; ${ }^{9}$ it has been shown to be effective in approximately $50 \%-70 \%$ of patients in a limited number of specialized centers. ${ }^{13}$

\section{Prognostic factors}

Favorable prognostic factors for successful surgery include magnetic resonance imaging (MRI) detection of the microadenoma, a well-defined tumor that is not invading either the basal dura or the cavernous sinus, histological confirmation of ACTH-secreting tumor, low postoperative serum cortisol levels, and long-lasting adrenal insufficiency after surgery. ${ }^{9,11,12,14}$

\section{Safety}

The most common complications of TS are diabetes insipidus, cerebrospinal fluid (CSF) leakage, vascular complications (occlusion and bleeding), and hypopituitarism. Total or partial hypophysectomy is associated with higher complication rates than selective tumor resection. ${ }^{9,12,15}$ Particularly, CSF leakage has been reported to occur more frequently during repeated TS than during the initial TS; this could depend on postoperative changes such as scar tissue but also as a result of a more aggressive surgical procedure in a usually small sella with a concave diaphragm. ${ }^{10}$ The higher rates of hypopituitarism after repeated TS can be expected because additional pituitary tissue is removed, even if the risk of hypopituitarism seems to be lower than reported rates several years after radiotherapy. ${ }^{16}$

\section{Radiotherapy}

In case of persistence or relapse of the disease, radiotherapy could be used. Fractionated external beam radiotherapy or stereotactic radiosurgery (SR) achieved control of hypercortisolism in approximately $50 \%-60 \%$ of patients within 3-5 years. ${ }^{17-20}$ Long-term follow-up is necessary to detect relapse, which can occur after an initial response to both types of radiotherapy. To date, comparison of SR with fractionated radiotherapy appears difficult due to different indications (such as, SR should presumably be reserved for patients with a small tumor volume and well delineated on MRI) and differences in length of follow-up. A recently reported ${ }^{21}$ series of patients with long-term follow-up (mean 96 months) after SR showed the following: (1) lower antisecretory efficacy of SR, (2) lower risk of adverse effects of SR, mainly in terms 
of hypopituitarism, and (3) a risk of late recurrence after SR, as opposed to conventional radiotherapy.

It is well documented that pituitary radiation reduces the risk of tumor growth (facilitated by bilateral adrenalectomy) but not in all patients emphasizing the need for continued regular monitoring by MRI studies.

The main drawbacks of both procedures are the slow onset of a beneficial effect, which requires effective antisecretory drugs during this period, the risk of hypopituitarism, and the potential for damage to the brain, optic apparatus or cranial nerves. ${ }^{17}$ The risk of second tumor formation after pituitary radiation is considered to be in the range of $1 \%-2 \%$ with conventional radiotherapy. ${ }^{22}$ Studies with a more prolonged follow-up will be necessary for defining the risk of second tumor after SR. The reports ${ }^{19,23}$ of development of cranial nerve deficit and visual loss after a second SR treatment suggest caution in repeating this procedure.

\section{Bilateral adrenalectomy}

Bilateral adrenalectomy is a definitive treatment that provides immediate control of hypercortisolism, and the morbidity can be minimized by the use of endoscopic approaches. However, since it determines a condition of permanent hypoadrenalism, it requires careful education and evaluation of the patient relatively to the need for lifelong glucocorticoid and mineralocorticoid replacement therapy. ${ }^{24}$ Moreover, because of the risk of developing Nelson syndrome, a corticotroph tumor progression, MRI scans, and ACTH evaluation have to be performed regularly in adrenalectomized patients. ${ }^{25}$

The second-line treatment for persistent hypercortisolism should be individualized but, generally, bilateral adrenalectomy may be indicated in patients with persistent hypercortisolism despite medical therapy or with intolerance to pharmacological agents or as an alternative to long-term medical treatment after pituitary radiotherapy and finally in women who wish to maintain fertility. ${ }^{9}$

\section{Medical management of CD}

At odds to other pituitary adenomas such as prolactinomas ${ }^{26}$ or growth hormone (GH)-secreting adenomas ${ }^{27}$ in which medical treatment has historically or more recently gained a significant space, in $\mathrm{CD}$, medical treatment is traditionally thought to have a marginal role. Nevertheless, there are numerous circumstances in which medical treatment of CD may be indicated. In fact, medical therapy is performed frequently before surgery to reduce the anesthesiological risk of the procedure, controlling the metabolic effects of severe hypercortisolism in analogy to what is done in the patients with acromegaly. ${ }^{28}$ Moreover, in patients in whom surgery has failed to control the disease, medical management is often essential to reduce or normalize hypercortisolemia, and should be performed before considering bilateral adrenalectomy. Medical therapy can also be useful in patients with $\mathrm{CD}$ while waiting for the complete effect of pituitary radiotherapy (that may take up to 10 years or even more). Finally, it is helpful as a palliative modality in rare CD patients with metastatic disease that is more common with cortisol-secreting adrenal cancer. ${ }^{29}$

Several drugs may affect adrenal function. They can be schematically divided into two types: adrenolytic agents and neuromodulatory agents (Tables 1 and 2). Of these, the former are still the most successful and therefore widely used, whereas the latter agents are currently undergoing active research.

\section{Adrenolytic agents Ketoconazole}

Ketoconazole is an imidazole derivative, which was originally developed as an oral antifungal agent. It is an inhibitor of sex-steroid and cortisol production by its action on C17-20 lyase and 11 betahydroxylase, respectively. It also inhibits 17-hydroxylase and 18 -hydroxylase activities. ${ }^{30}$ Treatment is usually started at a dose of $200 \mathrm{mg}$ twice daily, which may be increased up to $1,200 \mathrm{mg} / \mathrm{d}$ in four divided daily doses. ${ }^{31-33}$

\section{Efficacy}

The clinical signs and symptoms of hypercortisolism, including hypertension, hypokalemia, and diabetes mellitus are rapidly reversed, so antihypertensive and hypoglycemic drugs can often be discontinued. A meta-analysis of eight trials, involving different series of patients with $\mathrm{CD}$ treated with ketoconazole (dose range 400-1,200 mg daily), reported an average remission rate of $70 \%$ (range, $25 \%-93 \%$ ). ${ }^{34}$

\section{Side effects}

Reversible elevation of hepatic serum transaminases occurs in approximately $5 \%-10 \%$ of patients, with incidence of serious hepatic injury in approximately 1 of 15,000 cases. Histological changes can vary from predominantly cholestasis to extensive hepatocellular necrosis. Other adverse effects include skin rashes and gastrointestinal upset, and one must always be aware of the possibility to cause adrenal insufficiency. ${ }^{35}$ Owing to its sex-steroid inhibitory action, ketoconazole is particularly useful in women with hirsutism, which may be worsened by metyrapone. On the other hand, gynecomastia 
Table I Drugs with adrenolytic properties used in treatment of CD

\begin{tabular}{|c|c|c|c|}
\hline Agent & Doses & Results/peculiar effects & Side effects/limits \\
\hline Metyrapone & $750-6,000 \mathrm{mg} /$ daily & Effective & $\begin{array}{l}\text { Hypoadrenalism, nausea, abdominal pain, } \\
\text { hirsutism, acne } \\
\text { No longer available in United } \\
\text { States/compassionate use in Europe }\end{array}$ \\
\hline Ketoconazole & $400-1,200 \mathrm{mg} /$ daily & $\begin{array}{l}\text { Effective } \\
\text { Slow onset of action }\end{array}$ & $\begin{array}{l}\text { Gastrointestinal upset, rashes, elevation of } \\
\text { hepatic serum transaminases, gynecomastia, } \\
\text { reduced libido in men }\end{array}$ \\
\hline Aminoglutethimide & $250 \mathrm{mg} / 2-3$ times daily & $\begin{array}{l}\text { Less efficient in CD compared with } \\
\text { the other causes of CS, often used } \\
\text { as an adjunct to metyrapone }\end{array}$ & $\begin{array}{l}\text { Self-limited pruritic rash, nausea, somnolence, } \\
\text { dizziness, blurred vision, hypothyroidism, several } \\
\text { potential medication interactions } \\
\text { Cholestasis and bone marrow suppression are } \\
\text { rare side effects } \\
\text { No longer available }\end{array}$ \\
\hline Mitotane & $500 \mathrm{mg}-12 \mathrm{~g} /$ daily & $\begin{array}{l}\text { Effective (commonly used in cancer) } \\
\text { Gradual dose titration, taken during } \\
\text { meals }\end{array}$ & $\begin{array}{l}\text { Adrenal insufficiency, gastrointestinal upset, } \\
\text { neurological disturbances, elevation of hepatic } \\
\text { enzymes, hypercholesterolemia, hyperuricemia, } \\
\text { gynecomastia, prolonged bleeding time, change } \\
\text { in hormone-binding globulins, teratogenicity }\end{array}$ \\
\hline Etomidate & & Effective & Case reports in pediatric population \\
\hline
\end{tabular}

Abbreviations: $C D$, Cushing disease; CS, Cushing syndrome.

and reduced libido in men may be unacceptable. One further potential advantage is its inhibition of cholesterol synthesis described in a series of patients with Cushing syndrome. ${ }^{33}$

\section{Metyrapone}

Metyrapone inhibits the enzyme $11 \beta$-hydroxylase by blocking the production of cortisol from 11-deoxycortisol in the adrenal gland. The resultant relative decrease in cortisol may stimulate further ACTH secretion, increasing adrenal androgen and aldosterone precursors with weak mineralocorticoid activity. The drug is often started at thrice-daily doses of $250 \mathrm{mg}$, with titration up to a maximum of $6 \mathrm{~g} / \mathrm{d}$.

\section{Efficacy}

The inhibitory effect of metyrapone overcomes the increased drive to produce cortisol and has shown efficacy over an extended period of treatment. ${ }^{36}$ In a large study ${ }^{37}$ including 53 patients with $\mathrm{CD}$, a short-term control of mean serum

Table 2 Drugs centrally active (reduction of ACTH secretion) with therapeutic potential in CD

\begin{tabular}{|c|c|c|c|}
\hline Agent & Doses & Results/peculiar effects & Side effects/limits \\
\hline \multicolumn{4}{|l|}{ Somatostatin analogs } \\
\hline Octreotide & $100-300 \mu g /$ daily & Ineffective in clinical studies & Gastrointestinal discomfort, \\
\hline Pasireotide & $600 \mu \mathrm{g}$ twice daily & $\begin{array}{l}\text { Phase } 2 \text { study shows } \\
\text { promising results }\end{array}$ & $\begin{array}{l}\text { gall stones, hyperglycemia, } \\
\text { GH deficit? }\end{array}$ \\
\hline \multicolumn{4}{|l|}{ Dopamine agonists } \\
\hline Bromocriptine & 3-30 mg/daily & $\begin{array}{l}\text { Poor long-term results but } \\
\text { renewed interest }\end{array}$ & $\begin{array}{l}\text { Nausea and postural hypotension } \\
\text { Cardiac valve dysfunction? }\end{array}$ \\
\hline Cabergoline & $\mathrm{I}-7 \mathrm{mg} / \mathrm{wk}$ & $\begin{array}{l}\text { More efficacious than } \\
\text { bromocriptine }\end{array}$ & $\begin{array}{l}\text { Postural hypotension } \\
\text { Cardiac valve dysfunction? }\end{array}$ \\
\hline \multicolumn{4}{|c|}{ Histamine and serotonin antagonists } \\
\hline Cyproheptadine & 4-24 mg/daily & Small series, rarely effective & Sedation, weight gain \\
\hline \multicolumn{4}{|l|}{ 5-HT2 antagonist } \\
\hline Ritanserin & & $\begin{array}{l}\text { No sustained effects in most } \\
\text { patients }\end{array}$ & \\
\hline \multicolumn{4}{|c|}{ PPAR- $\gamma$ receptor agonists } \\
\hline Rosiglitazone & 4-16 mg/daily & In vitro success not & \\
\hline Pioglitazone & $45 \mathrm{mg}$ daily & reproduced in clinical practice & \\
\hline
\end{tabular}

Abbreviations: ACTH, adrenocorticotropin hormone; CD, Cushing disease; GH, growth hormone; PPAR- $\gamma$, peroxisome proliferator-activated receptor- $\gamma$; $5-H T$, 5-hydroxytryptamine. 
cortisol level $(\leq 400 \mathrm{nmol} / \mathrm{L})$ was obtained in $75 \%$ of patients compared with effective long-term control in $83 \%$ of 24 patients who were given metyrapone (mean, 2,250 mg/d; median, 27 months) following pituitary irradiation.

\section{Side effects}

The main side effects are hirsutism, acne (which can clearly be problematic in women), dizziness, and gastrointestinal upset. Hypoadrenalism remains the most important potential problem, and careful monitoring of treatment and education of the patient is required. Hypokalemia, edema, and hypertension due to raised mineralocorticoids are infrequent but may require cessation of therapy. ${ }^{32,37}$

Of note, metyrapone is not commercially available but can be provided for compassionate use by contacting the manufacturer directly.

\section{Aminoglutethimide}

Aminoglutethimide, which is no longer available in the United States and Europe, often used at a dose of $250 \mathrm{mg}$ 2-3 times daily, prevents conversion of cholesterol to pregnenolone. Thus, it inhibits not only cortisol production but also estrogen and aldosterone production.

\section{Efficacy}

In the largest published study of 66 patients with Cushing syndrome, ${ }^{38}$ a favorable response was seen in 14 of 33 patients with CD. However, aminoglutethimide seems to be less efficient in CD compared with the other causes of Cushing syndrome. This may be due to an increase in ACTH overcoming the enzymatic blockade or by hepatic enzyme induction that increases its own metabolism leading also to tolerance with continued treatment and explaining some side effects. ${ }^{32}$ Because of its limited efficacy, aminoglutethimide is now most often used as an adjunct to metyrapone for reducing the doses and, thus, the toxicity of the drug. ${ }^{39}$

\section{Side effects}

The primary side effect is a generalized, self-limited pruritic rash that is usually manageable with antihistamine drugs. Nausea, somnolence, dizziness, and blurred vision may occur. As the drug blocks thyroid hormone synthesis, hypothyroidism is a well-known side effect. Cholestasis and bone marrow suppression are rare side effects. Being a strong inducer of several cytochrome P450 enzymes, aminoglutethimide may have several potential interactions with other medications. Because this medication increases the metabolism of dexamethasone but not that of hydrocortisone, the latter is often used if steroid replacement is needed. ${ }^{40}$

\section{Mitotane}

Mitotane is often started at $250-500 \mathrm{mg}$ nightly with slow escalation of the dose up to $4-12 \mathrm{~g} / \mathrm{d}$. This drug inhibits $11 \alpha$-hydroxylase, 18 -hydroxylase, $3 \alpha$-hydroxylase, hydroxysteroid dehydrogenase, and several cholesterol side-chain cleavage enzymes. At doses greater than $4 \mathrm{~g} / \mathrm{d}$, it has toxic effect because its metabolite binds macromolecules in adrenal cortical cell mitochondria, leading to their destruction and cellular necrosis. Because of this property, its primary use is in patients with adrenocortical carcinoma. ${ }^{41}$

\section{Efficacy}

In a large historical study ${ }^{42}$ including $46 \mathrm{CD}$ patients receiving mitotane from 4 to $12 \mathrm{~g} / \mathrm{d}$, remission occurred in 38 cases (83\%) in 8 months. All 16 patients who received both mitotane and pituitary radiotherapy were controlled. In another study ${ }^{43}$ with adjunctive radiotherapy, remission was observed in 29 of 36 patients $(81 \%)$, and in 17 patients (47\%) long-term mitotane therapy was not necessary. In this last study, lowerdose mitotane regimen (up to $4 \mathrm{~g} / \mathrm{d}$ ) was used to reducing side effects. These studies not only highlighted the slow onset of action of mitotane but also showed that the adrenolytic effect can persist even after the drug is stopped.

\section{Side effects}

Side effects of this medication may limit its use. In fact, with doses as high as those used in carcinoma, the incidence of adrenal insufficiency and adverse effects, particularly gastrointestinal upset (57\%), is significant. Of note, patients who undergo mitotane treatment, similarly to patients submitted to bilateral adrenalectomy, are at risk of developing Nelson syndrome if they do not receive pituitary radiotherapy. ${ }^{36}$ Other side effects include neurological disturbances (ataxia, vertigo, confusion, and language impairment), elevation of hepatic enzymes, hypercholesterolemia, hyperuricemia, gynecomastia, prolonged bleeding time, and change in hormone-binding globulins. ${ }^{32}$ Hypercholesterolemia responds to treatment with 3-hydroxy-3-methylglutaryl-CoA reductase inhibitors. ${ }^{44}$ Finally, the drug is contraindicated in pregnant women for its teratogenicity. ${ }^{45}$

\section{Etomidate}

Etomidate, a commonly used short-acting intravenous anesthetic, is a potent inhibitor of $11 \alpha$-hydroxylase and an inhibitor of $17 \alpha$-hydroxylase.

There have been a number of case reports on the successful use of etomidate in controlling hypercortisolemia in seriously ill patients with $\mathrm{CD}$ even in the pediatric population. ${ }^{46-48}$ 


\section{Neuromodulatory agents}

As stated above, for several reasons (mechanism of action and side effects), adrenolytic agents are more suitable for short-term adjunctive treatment. Therefore, the search for more "pathogenetic" drugs, which thus may act on ACTH secretion at the pituitary adenoma level without interfering with other hormone synthesis and may even be used as primary treatment, is still open.

In this vein, it is worthwhile to dedicate a specific section of this review to neuromodulatory centrally active agents such as somatostatin (SS) analogs and dopamine agonists (DAs).

\section{SS analogs}

Preclinical studies: SS receptors in normal corticotroph cells and in vitro studies with SS analogs

in corticotroph cell lines and adenomas

Rat pituitary corticotrophs express multiple somatostatin receptors (sst), including sst2 and sst5 ${ }^{49}$ but treatment of cultured rat corticotrophs with native SS-14 does not result in inhibition of ACTH release. ${ }^{50}$ However, SS-14 is able to decrease ACTH release when rat pituitary cells are cultured in glucocorticoid-free media. ${ }^{51}$ Therefore, it can be hypothesized that the presence of glucocorticoids reduces the inhibitory effects of native $\mathrm{SS}$ and traditional SS analogs on ACTH release through the down regulation of the SS binding sites. ${ }^{52} \mathrm{~A}$ number of studies have indicated that, in the murine AtT-20 cells, sst 2 and sst 5 are principally involved in the regulation of ACTH release. More recently, it was found that sst5-targeting agonists were more effective than sst2-targeting agonists in inhibiting ACTH release; this could depend on dexamethasone decreasing sst 2 but not sst 5 expression. In fact, octreotide (that binds preferentially sst 2 but only modestly sst5), but not pasireotide (a universal ligand with high binding affinity for sst1, sst2, sst3, and sst5), lost most of its ACTH-inhibiting potential with glucocorticoid pretreatment ${ }^{53}$ or in patients with $\mathrm{CD}$ in vivo. ${ }^{54}$ Two studies ${ }^{5,56}$ investigated the effects of SS analogs in human corticotroph adenoma tissues; a superior ACTH inhibition by pasireotide as compared with octreotide ${ }^{55}$ and a dissociation in some adenomas between the antisecretory and antiproliferative effects of pasireotide ${ }^{56}$ were reported similar to what is observed in acromegaly. ${ }^{57,58}$

\section{Efficacy in clinical studies}

In clinical studies, the currently available SS analogs, octreotide and lanreotide, which are effective in the treatment of acromegaly, ${ }^{59}$ are ineffective in CD. ${ }^{60-62}$ Many authors ${ }^{62-65}$ have found that, in Nelson syndrome, an expanding ACTHproducing pituitary adenoma after bilateral adrenalectomy may respond to octreotide with reduction in circulating ACTH levels. This observation could be explained with the lack of glucocorticoid-induced down-regulation of sst2, as mentioned above. ${ }^{52}$

A Phase II, proof of concept, open-label, single-arm, multicenter study of pasireotide in CD has been recently published. ${ }^{66}$ Patients self-administered pasireotide $600 \mu \mathrm{g}$ subcutaneously twice daily for 15 days at 9:00 AM and 9:00 PM. The selected dose was based on pharmacokinetic analysis. Dose adjustments were permitted for patients who were unable to tolerate the protocol-specified dose $(150 \mu \mathrm{g}$ per injection). The primary efficacy population consisted of 29 patients from a total of 39 patients recruited from 10 centers. At diagnosis, urinary free cortisol (UFC) had to be at least two times above the upper limit of normal. UFC levels decreased in $76 \%$ of patients but only $17 \%$ (5 of them) normalized UFC levels after 15 days. Overall, the mean UFC level decreased from baseline by $44.5 \%$. In addition, reduction in serum cortisol and plasma ACTH was observed during the pasireotide treatment. There was a trend $(P=0.102)$ toward a lower baseline UFC level being predictive of a response to pasireotide. There were no significant differences in baseline $\mathrm{ACTH}$ area under the curve $\left(\mathrm{AUC}_{0-8 \mathrm{~h}}\right)$ values between UFC responders and nonresponders. A 1.8fold higher plasma concentration and 1.3-fold higher plasma exposure of pasireotide were observed in UFC responders than in nonresponders suggesting a role of pasireotide exposure in determining reponse to treatment.

\section{Safety and tolerability}

The most common events with pasireotide were drug-related gastrointestinal disorders ( $54 \%$ of patients), mainly diarrhea (44\%), nausea (23\%), and abdominal pain (18\%). Hyperglycemia, another potential effect of SS analogs, ${ }^{67}$ occurred in 14 patients (36\%) and 1 of them, with a pre-existing history of diabetes mellitus, discontinued the treatment. Analysis of insulin and glucagon levels at baseline vs during treatment indicated that pasireotide administration was followed by initial suppression of insulin but did not significantly influence glucagon release.

Another potential problem of pasireotide in CD might be its effects on GH and insulin-like growth factor (IGF)-1 levels in CD. In preclinical studies, pasireotide significantly decreased GH and IGF-1 levels. In patients with CD, hypercortisolism per se causes a relative GH deficiency (GHD), ${ }^{68,69}$ and therefore, these patients may be at greater risk to become GH deficient. Future clinical studies are needed to clarify this aspect. 


\section{Dopamine agonists}

Preclinical studies: DA receptors in normal corticotroph cells and in vitro studies with DA in corticotroph adenomas

In humans, no conclusive data exist whether $\mathrm{ACTH}$ release is directly regulated by DA receptors in normal corticotroph cells. ${ }^{70}$ On the other hand, in rats, it is known that the intermediate lobe in the pituitary is under tonic inhibitory control of the hypothalamic dopaminergic neurons. ${ }^{71}$ In humans, the intermediate lobe is a rudimentary structure although it has been suggested to maintain some biological functions, ${ }^{72,73}$ corticotroph adenomas arising from the intermediate lobe may be more likely to respond to the classical dopaminergic agent bromocriptine. ${ }^{70}$

In 2004, Pivonello et al ${ }^{74}$ showed that the majority ( $80 \%$ ) of human corticotroph adenomas express the $\mathrm{D}_{2}$ receptors as demonstrated by immunohistochemistry and reverse transcriptasepolymerase chain reaction. Moreover, functional studies in vitro correlated very well with the $\mathrm{D}_{2}$ expression data, and adenomas with high $\mathrm{D}_{2}$ expression responded well to either bromocriptine or the newest dopaminergic cabergoline with acute inhibition of ACTH release by $43 \%$ to $60 \%$.

\section{Efficacy in clinical studies}

Although initial reductions in ACTH levels were evident in almost half of patients with $\mathrm{CD}$ in response to bromocriptine administration, a sustained response occurred only in a small percentage of patients. ${ }^{70}$ Compared with bromocriptine, cabergoline binds with even greater specificity and affinity to $D_{2}$ receptors and has a longer duration of action. In the study by Pivonello et $\mathrm{al}^{74} 20$ patients with $\mathrm{CD}$ were treated with cabergoline at a dose of 1-3 $\mathrm{mg} / \mathrm{wk}$ for 3 months with a significant decrease in UFC in $60 \%$ of the patients and even complete normalization in $40 \%$ of them. Several other case reports suggested that at least in some patients with $\mathrm{CD}$, cabergoline could control cortisol hypersecretion. ${ }^{75,76}$ More recently, Pivonello et $\mathrm{al}^{77}$ in the extension of a previously reported preliminary study, evaluated for the first time the results of chronic cabergoline treatment in $\mathrm{CD}$. The results of the study demonstrated that a 24-month treatment with cabergoline, at doses between 1 and $7 \mathrm{mg} / \mathrm{wk}$, induced or maintained control of cortisol secretion in $40 \%$ and induced tumor shrinkage in $20 \%$ of a group of 20 patients with $\mathrm{CD}$, improving hypertension and glucose tolerance in the majority of patients, regardless of the normalization of cortisol secretion.

\section{Safety and tolerability}

Concerning the long-term study with cabergoline, ${ }^{77}$ no severe side effects were documented. However, hypotension associated with severe asthenia was observed in two patients, who stopped the drug after 12 and 18 months of treatment. A transient moderate asthenia was registered in four patients, whereas a transient mild dizziness with nausea was reported by another patient but these latter side effects did not require treatment withdrawal. It is noteworthy that no significant cardiac valve dysfunction was found in this study, with the exception of a slight worsening of tricuspid regurgitation in one patient. This is important because high-dose, longterm cabergoline therapy has been recently described to be associated with an increased prevalence of cardiac valve insufficiency ${ }^{25,26}$ not only in Parkinson disease. ${ }^{78}$ However, because of the short period of follow-up so far available (maximum 2 years), no firm conclusion on this side effect of cabergoline in CD may be drawn.

\section{Combined treatment with SS and DA agonists}

Considering the presence of both sst and DA receptors in human corticotroph adenomas, the cotreatment with SS analogs and DA agonists (pasireotide + cabergoline) or perhaps, in the future, the administration of SS-DA chimeric compounds, such as BIM-23A760, already tested in vitro in $\mathrm{GH}$-secreting adenomas, seem to be a reasonable approach. Very recently, pasireotide monotherapy has been shown to induce sustained normalization of the level of UFC in 5 of 17 patients studied (29\%). The addition of cabergoline normalized UFC values in another 4 of 17 patients (24\%). At day 60,8 of 17 patients (47\%) still had elevated UFC levels with the pasireotide-cabergoline combination, although a trend toward normalization was observed in all except one, with a mean decrease of $48 \% \pm 6 \%$ in the level of UFC. ${ }^{79}$

\section{PPAR- $\gamma$ agonists}

In 2002, the nuclear hormone receptor, peroxisome proliferator-activated receptor- $\gamma$ (PPAR- $\gamma$ ), was identified in ACTH-secreting pituitary tumors. Development of murine corticotroph tumors, generated by subcutaneous injection of ACTH-secreting AtT-20 cells, was prevented in 4 of 5 mice treated with the PPAR- $\gamma$ receptor agonist rosiglitazone, and ACTH and corticosterone levels were suppressed in all treated mice. ${ }^{80}$

\section{Efficacy and side effects}

In a study of 10 patients, four prior to surgery, four following relapse after surgery, and two immediately after failed surgery treated with 4-16 mg of rosiglitazone for 1-8 months (median 3 months), and no consistent reductions in UFC levels were found. ${ }^{81}$ 
Side effects reported included edema, weight gain, somnolence, and increased hirsutism. In a larger study, 14 patients with active $\mathrm{CD}$ ( 7 untreated and 7 after unsuccessful surgery) were treated with $8-16 \mathrm{mg}$ of rosiglitazone for $1-7$ months. ${ }^{82}$ In six patients, 24-hour UFC was significantly lowered and two of them also noted clinical improvement at 7-month follow-up. Relatively, to side effects, one patient developed hypercholesterolemia. Although most studies used rosiglitazone, pioglitazone has also been tried; ${ }^{83}$ in none of five patients with $\mathrm{CD}$ treated with pioglitazone, $45 \mathrm{mg}$ for 30 days, any UFC responses were observed. Therefore, clinical trials of PPAR $-\gamma$ agonists in CD have lead to disappointing results, unfortunately, failing to reproduce the success observed in the in vitro and mouse model. It should be recalled that human corticotroph tumors have a different proliferative potential than murine AtT-20 cells, as the latter quickly replicate and grow when implanted into nude mice. Conversely, human pituitary ACTH-secreting tumors do not exhibit such a pronounced growth pattern and indeed are typically small in size even in patients with long-standing CD. If the ACTH-lowering effect of rosiglitazone is primarily due to its antiproliferative effect, a long time frame would be necessary for a decrease in ACTH levels to occur in human pituitary tumors. Furthermore, rosiglitazone might be more effective in ACTH-secreting macroadenomas than in microadenomas. This possibility remains to be investigated as none of the patients with CD included in clinical trials presented with macroadenoma. An additional consideration is that the dose of rosiglitazone used in clinical studies was far less than that used in mice with experimental $\mathrm{CD},{ }^{81}$ which attained 10-50 fold greater concentrations of the drug. Finally, a potential concern for the long-term use of rosiglitazone in $\mathrm{CD}$ is its pro-osteoporotic effects already observed in diabetic patients. ${ }^{84}$

\section{Retinoic acid}

The antiproliferative action and the ACTH and corticosterone inhibition induced by retinoic acid in vitro were confirmed in vivo in mice with experimental ACTH-secreting tumors and in dogs with CD. However, the efficacy of these treatments in patients with $\mathrm{CD}$ still needs to be tested in clinical trials. ${ }^{85}$

\section{Glucocorticoid receptor antagonists}

Finally, in analogy with acromegaly where the peripheral GH antagonist pegvisomant has been successfully used, ${ }^{26,86}$ an antagonist to block the peripheral effects of glucocorticoids may be engineered for the future. So far, there is no significant experience reported with the glucocorticoid receptor antagonist mifepristone (RU 486) in CD, and assessment of its efficacy in the absence of a biochemical marker is challenging. ${ }^{9}$ In a European retrospective study, clinical signs of hypercortisolism improved rapidly in three of four patients with CD treated with mifepristone but one developed hypertension and severe hypokalemia during the therapy. ${ }^{87}$

\section{Therapy for the complications of CD Cardiovascular complications}

Arterial hypertension is a common feature in CD (70\%-80\% of the patients) and may be the first sign of CD. Conventional antihypertensive therapy (thiazides, angiotensin-converting enzyme inhibitors, and calcium antagonists are generally considered as first choice) may be only partially effective, whereas the additional successful use of cortisol-lowering agents may improve blood pressure control. ${ }^{88}$ Hypertension remits in most patients after successful treatment, but in some cases, it may persist probably because of microvessel remodeling and/or underlying essential hypertension. ${ }^{89}$

Epidemiological studies show that $20 \%-30 \%$ of patients with CD have diabetes mellitus, whereas impaired glucose tolerance is reported in $30 \%-60 \%$ of them..$^{90}$ The impairment of glucose metabolism generally resolves with normalization of cortisol levels because hypercortisolism per se is the causative factor of hyperglycemia. However, treatment with SS analogs, as previously reported, may theoretically cause the appearance or the worsening of diabetes. ${ }^{67}$ Diabetes should be controlled by oral hypoglycemic drugs or, more frequently, by insulin therapy.

The metabolic syndrome of CD associated with the hypercoagulability state determines an increased cardiovascular risk that may persist after cure and is the principal cause of death in CD patients with persistent hypercortisolism. In the absence of prospective randomized trials, there is general agreement that patients with CD should be given heparin during inferior petrosal sinus sampling and low-dose heparin treatment should be considered in the immediate perioperative period. ${ }^{1}$

\section{Osteoporosis}

Several authors reported that glucocorticoid-induced osteoporosis is reversible. ${ }^{8,91}$ Patients with Cushing syndrome had a restoration of osteoblast activity, evaluated on the basis of increased osteocalcin levels, after 6 months of disease cure, without achieving any relevant changes in bone mineral density (BMD). Thereafter, remarkable improvement of BMD can be observed in almost all patients after a normalization period of cortisol levels lasting $12-36$ months. ${ }^{92}$ Similarly, in a retrospective study of 17 patients with Cushing syndrome, 
after several years of cure, normalization of BMD at lumbar spine and femoral neck was reported..$^{93}$

Moreover, bone impairment in patients with childhood and adulthood onset CD can be partly, but not completely, reversed 2 years after normalization of cortisol levels, suggesting that longer recovery times or additive therapeutic approaches are necessary to maximize peak bone mass in children and restore bone mass in adults with $\mathrm{CD} .{ }^{94}$

The mechanism of the recovery in BMD can only be speculative. Glucocorticoids rapidly and sharply increase bone resorption (this is considered the major contributor to the almost immediate increase in fracture risk caused by excess corticosteroid levels) but importantly, particularly in the longterm, they diminish bone formation rate. ${ }^{95,96}$ This latter effect as evaluated by circulating levels of osteocalcin is rapidly reversible with normalization of hypercortisolism. A second important contribution to this recovery may be the preservation of trabecular architecture despite trabecular thinning in steroidinduced osteoporosis, so the framework in which the osteoblasts can synthesize new bone is intact. This contrasts with the loss of trabeculae that occurs in other forms of osteoporosis. ${ }^{1}$

In patients treated with ketoconazole after unsuccessful pituitary surgery, even when normalization of cortisol levels was achieved, BMD remained low; this finding could be in line with slow and difficult recovery of bone metabolism after cure of $\mathrm{CD}$ but, alternatively, could suggest an interfering effect of ketoconazole on bone metabolism..$^{97}$ Overall, it can be concluded that the recovery of bone loss is gradual, taking approximately 10 years to complete. In the meanwhile, patients with severe osteopenia are exposed to a high risk of fracture. Therefore, in these patients, the use of antiresorptive medications could be useful. In fact, recent data suggest that alendronate may induce a more rapid improvement in BMD than cortisol normalization alone, probably by restoring the balance between bone formation and resorption. In addition, alendronate treatment was also shown to be useful in patients with persistent postsurgical hypercortisolism as it prevented further bone loss. ${ }^{98}$

Although there are no large prospective studies in patients with $\mathrm{CD}$, additional therapies, such as calcium and vitamin D supplementation and sex hormone replacement in men or women with hypogonadism, may likely be beneficial. ${ }^{1} \mathrm{New}$ data on the use of anabolic therapies (parathyroid hormone and $\mathrm{GH})^{99,100}$ in glucocorticoid-induced osteoporosis are encouraging and could be also perspectively applied to patients with endogenous hypercortisolism. ${ }^{101-103}$

Considering that the risk of fractures persists sometime after cure of hypercortisolism, the decision to discontinue antiresorptive therapy should be based at least on clinical monitoring and dual energy X-ray absorptiometry measurements. ${ }^{1}$ However, because BMD is not a good predictor of fractures in $\mathrm{CD}$, a spine X-ray could also be indicated. ${ }^{104}$

\section{Hypopituitarism in cured CD}

Hypopituitarism is a well-known possible complication of surgery and radiotherapy for pituitary diseases. As previously stated, several treatments of CD may induce hypopituitarism. However, although the necessity of substitutive treatment of several tropin deficiency, including ACTH, is intuitive, there is still, for several reasons, interest and debate surrounding prevalence, diagnosis, and treatment of GHD. In fact, even subtle excess of glucocorticoids inhibits GH secretion; ${ }^{105}$ indeed, GH secretion is impaired in both children and adult patients with $\mathrm{CD} .{ }^{106}$ In contrast, to what extent recovery of GH secretion follows the normalization of cortisol levels is less well established. ${ }^{107}$ This uncertainty is due to the fact that patients were often tested shortly after remission of hypercortisolism, and remission was achieved by several treatment modalities, including radiation therapy, which is known to progressively impair anterior pituitary function over time. Further, patients cured from CD frequently do not normalize body weight and this may confound the interpretation of GH status. ${ }^{108}$

Some studies reported the presence of GHD in a high percentage of $\mathrm{CD}$ after long-term remission of hypercortisolism obtained by surgery alone. ${ }^{109} \mathrm{~A}$ retrospective cross-sectional study $^{110}$ has been recently published with the comparison of cured patients with $\mathrm{CD}(\mathrm{n}=684,74 \%$ women $)$ and nonfunctioning pituitary adenoma (NFPA; $\mathrm{n}=2,990,39 \%$ women) treated for 3 years with GH after the diagnosis of GHD. ${ }^{111,112}$ The study showed a significant delay in GHD diagnosis in the $\mathrm{CD}$ group, who had a higher prevalence of hypertension, fractures, and diabetes mellitus. In untreated GHD, comorbidities, including impairment of quality of life, were more prevalent in patients with previous CD. Overall, both groups responded similarly to GH replacement, suggesting that patients with GHD due to CD may benefit from GH to the same extent as those with GHD due to NFPA. On the other hand, improvements in BMD occur later in patients with prolactinomas and $\mathrm{CD}$ treated with $\mathrm{GH}$ when compared with NFPA. ${ }^{113}$

Finally, when the long-term complications were considered, GH-treated patients with previous hypercortisolism showed an increased risk of metabolic syndrome, cardiovascular disease, and cerebrovascular disease as compared with GH-treated patients with previous NFPA. ${ }^{114}$ 


\section{Conclusion}

$\mathrm{CD}$ is a severe and complex clinical syndrome, which needs aggressive and possibly rapid curative treatment due to its long-term sequelae. Unfortunately, current therapeutic options do not achieve cure in a relevant part of patients even in the hands of the most specialized centers. Therefore, the search for new medical effective tools is still open, and already promising results have been obtained. Finally, these considerations emphasize the need of a careful follow-up and aggressive treatment of complications in CD particularly in patients with difficult control of the disease but also interestingly and somewhat paradoxically in patients with cured CD.

\section{Disclosure}

The authors report no conflicts of interest in this work.

\section{References}

1. Arnaldi G, Angeli A, Atkinson AB, et al. Diagnosis and complications of Cushing's syndrome: a consensus statement. $J$ Clin Endocrinol Metab. 2003;88(12):5593-5602.

2. Pivonello R, de Martino MC, de Leo M, Lombardi G, Colao A. Cushing's syndrome. Endocrinol Metab Clin North Am. 2008; 37(1):135-149.

3. Canalis E, Mazziotti G, Giustina A, Bilezikian JP. Glucocorticoidinduced osteoporosis: pathophysiology and therapy. Osteoporos Int. 2007;18(10):1319-1328.

4. Lindholm J, Juul S, Jørgensen JO, et al. Incidence and late prognosis of Cushing's syndrome: a population-based study. J Clin Endocrinol Metab. 2001;86(1):117-123.

5. Mancini T, Kola B, Mantero F, Boscaro M, Arnaldi G. High cardiovascular risk in patients with Cushing's syndrome according to $1999 \mathrm{WHO} /$ ISH guidelines. Clin Endocrinol (Oxf). 2004;61(6):768-777.

6. Arnaldi G, Mancini T, Polenta B, Boscaro M. Cardiovascular risk in Cushing's syndrome. Pituitary. 2004;7(4):253-256.

7. Mazziotti G, Angeli A, Bilezikian JP, Canalis E, Giustina A. Glucocorticoid-induced osteoporosis: an update. Trends Endocrinol Metab. 2006;17(4):144-149.

8. Mancini T, Doga M, Mazziotti G, Giustina A. Cushing's syndrome and bone. Pituitary. 2004;7(4):249-252.

9. Biller BM, Grossman AB, Stewart PM, et al. Treatment of adrenocorticotropin-dependent Cushing's syndrome: a consensus statement. J Clin Endocrinol Metab. 2008;93(7):2454-2462.

10. Wagenmakers MA, Netea-Maier RT, van Lindert EJ, Timmers HJ, Grotenhuis JA, Hermus AR. Repeated transsphenoidal pituitary surgery (TS) via the endoscopic technique: a good therapeutic option for recurrent or persistent Cushing's disease (CD). Clin Endocrinol (Oxf). 2009;70(2):274-280.

11. Atkinson AB, Kennedy A, Wiggam MI, McCance DR, Sheridan B. Long-term remission rates after pituitary surgery for Cushing's disease: the need for long-term surveillance. Clin Endocrinol (Oxf). 2005;63(5):549-559.

12. Hammer GD, Tyrrell JB, Lamborn KR, et al. Transsphenoidal microsurgery for Cushing's disease: initial outcome and long-term results. J Clin Endocrinol Metab. 2004;89(12):6348-6357.

13. Hofmann BM, Hlavac M, Kreutzer J, Grabenbauer G, Fahlbusch R. Surgical treatment of recurrent Cushing's disease. Neurosurgery. 2006; 58(6): 1108-1118.

14. Sonino N, Zielezny M, Fava GA, Fallo F, Boscaro M. Risk factors and long-term outcome in pituitary-dependent Cushing's disease. $J$ Clin Endocrinol Metab. 1996;81(7):2647-2652.
15. Mampalam TJ, Tyrrell JB, Wilson CB. Transsphenoidal microsurgery for Cushing disease. A report of 216 cases. Ann Intern Med. 1988; 109(6):487-493.

16. Liu JK, Fleseriu M, Delashaw JB Jr, Ciric IS, Couldwell WT. Treatment options for Cushing disease after unsuccessful transsphenoidal surgery. Neurosurg Focus. 2007;23(3):E8.

17. Vance ML. Cushing's disease: radiation therapy. Pituitary. 2009;12(1):11-14.

18. Estrada J, Boronat M, Mielgo M, et al. The long-term outcome of pituitary irradiation after unsuccessful transsphenoidal surgery in Cushing's disease. N Engl J Med. 1997;336(3):172-177.

19. Jagannathan J, Sheehan JP, Pouratian N, Laws ER, Steiner L, Vance ML. Gamma knife surgery for Cushing's disease. J Neurosurg. 2007; 106(6):980-987.

20. Castinetti F, Régis J, Dufour H, Brue T. Role of stereotactic radiosurgery in the management of pituitary adenomas. $J$ Clin Endocrinol Metab. 2010;6(4):214-223.

21. Castinetti F, Nagai M, Morange I, et al. Long-term results of stereotactic radiosurgery in secretory pituitary adenomas. $J$ Clin Endocrinol Metab. 2009;94(9):3400-3407.

22. Minniti G, Traish D, Ashley S, Gonsalves A, Brada M. Risk of second brain tumor after conservative surgery and radiotherapy for pituitary adenoma: update after an additional 10 years. $J$ Clin Endocrinol Metab. 2005;90(2):800-804.

23. Pollock BE, Nippoldt TB, Stafford SL, Foote RL, Abboud CF. Results of stereotactic radiosurgery in patients with hormone-producing pituitary adenomas: factors associated with endocrine normalization. J Neurosurg. 2002;97(3):525-530.

24. Chow JT, Thompson GB, Grant CS, Farley DR, Richards ML, Young WF Jr. Bilateral laparoscopic adrenalectomy for corticotrophindependent Cushing's syndrome: a review of the Mayo Clinic experience. Clin Endocrinol (Oxf). 2008;68(4):513-519.

25. Assié G, Bahurel H, Coste J, et al. Corticotroph tumor progression after adrenalectomy in Cushing's Disease: a reappraisal of Nelson's syndrome. J Clin Endocrinol Metab. 2007;92(1):172-179.

26. Mancini T, Casanueva FF, Giustina A. Hyperprolactinemia and prolactinomas. Endocrinol Metab Clin North Am. 2008;37(1):67-99, viii.

27. Giustina A, Chanson P, Bronstein MD, et al. A consensus on criteria for cure of acromegaly. J Clin Endocrinol Metab. 2010;95(7): 3141-3148.

28. Melmed S, Casanueva F, Cavagnini F, et al. Consensus statement: medical management of acromegaly. Eur J Endocrinol. 2005;153(6): 737-740.

29. Schteingart DE. Drugs in the medical treatment of Cushing's syndrome. Expert Opin Emerg Drugs. 2009;14(4):661-671.

30. Sonino N. The use of ketoconazole as an inhibitor of steroid production. N Engl J Med. 1987;317(13):812-818.

31. Sonino N, Boscaro M. Medical therapy for Cushing's disease. Endocrinol Metab Clin North Am. 1999;28(1):211-222.

32. Morris D, Grossman A. The medical management of Cushing's syndrome. Ann N Y Acad Sci. 2002;970:119-133.

33. Sonino N, Boscaro M, Paoletta A, Mantero F, Ziliotto D. Ketoconazole treatment in Cushing's syndrome: experience in 34 patients. Clin Endocrinol (Oxf). 1991;35(4):347-352.

34. Engelhardt D, Weber MM. Therapy of Cushing's syndrome with steroid biosynthesis inhibitors. J Steroid Biochem Mol Biol. 1994; 49(4-6):261-267.

35. Stricker BH, Blok AP, Bronkhorst FB, van Parys GE, Desmet VJ. Ketoconazole-associated hepatic injury. A clinicopathological study of 55 cases. J Hepatol. 1986;3(3):399-406.

36. Gross BA, Mindea SA, Pick AJ, Chandler JP, Batjer HH. Medical management of Cushing disease. Neurosurg Focus. 2007;23(3):E10.

37. Verhelst JA, Trainer PJ, Howlett TA, et al. Short and long-term responses to metyrapone in the medical management of 91 patients with Cushing's syndrome. Clin Endocrinol (Oxf). 1991;35(2):169-178.

38. Misbin RI, Canary J, Willard D. Aminoglutethimide in the treatment of Cushing's syndrome. J Clin Pharmacol. 1976;16(11-12):645-651. 
39. Child DF, Burke CW, Burley DM, Rees LH, Fraser TR. Drug controlled of Cushing's syndrome: combined aminoglutethimide and metyrapone therapy. Acta Endocrinol (Copenh). 1976;82:330-341.

40. Santen RJ, Misbin RI. Aminoglutethimide: review of pharmacology and clinical use. Pharmacotherapy. 1981;1(2):95-120.

41. Terzolo M, Angeli A, Fassnacht M, et al. Adjuvant mitotane treatment for adrenocortical carcinoma. $N$ Engl J Med. 2007;356(23): 2372-2380.

42. Luton JP, Mahoudeau JA, Bouchard P, et al. Treatment of Cushing's disease by O,p'DDD. Survey of 62 cases. N Engl J Med. 1979;300(9): 459-464.

43. Schteingart DE, Tsao HS, Taylor CI, McKenzie A, Victoria R, Therrien BA. Sustained remission of Cushing's disease with mitotane and pituitary irradiation. Ann Intern Med. 1980;92(5):613-619.

44. Maher VM, Trainer PJ, Scoppola A, Anderson JV, Thompson GR, Besser GM. Possible mechanism and treatment of o,p'DDD-induced hypercholesterolaemia. $Q J$ Med. 1992;84(305):671-679.

45. Leiba S, Weinstein R, Shindel B, et al. The protracted effect of o,p'DDD in Cushing's disease and its impact on adrenal morphogenesis of young human embryo. Ann Endocrinol (Paris). 1989;50(1):49-53.

46. Herrmann BL, Mitchell A, Saller B, et al. Transsphenoidal hypophysectomy of a patient with an ACTH-producing pituitary adenoma and an "empty sella" after pretreatment with etomidate. Dtsch Med Wochenschr. 2001;126(9):232-234.

47. Mettauer N, Brierley J. A novel use of etomidate for intentional adrenal suppression to control severe hypercortisolemia in childhood. Pediatr Crit Care Med. 2009;10(3):e37-e40.

48. Greening JE, Brain CE, Perry LA, et al. Efficient short-term control of hypercortisolaemia by low-dose etomidate in severe paediatric Cushing's disease. Horm Res. 2005;64(3):140-143.

49. Mezey E, Hunyady B, Mitra S, et al. Cell specific expression of the sst2 A and sst5 somatostatin receptors in the rat anterior pituitary. Endocrinology. 1998;139(1):414-419.

50. Kraicer J, Gajewski TC, Moor BC. Release of pro-opiomelanocortinderived peptides from the pars intermedia and pars distalis of the rat pituitary: effect of corticotrophin-releasing factor and somatostatin. Neuroendocrinology. 1985;41(5):363-373.

51. Lamberts SW, Zuyderwijk J, den Holder F, van Koetsveld P, Hofland L. Studies on the conditions determining the inhibitory effect of somatostatin on adrenocorticotropin, prolactin and thyrotropin release by cultured rat pituitary cells. Neuroendocrinology. 1989;50(1):44-50.

52. Schonbrunn A. Glucocorticoids down-regulate somatostatin receptors on pituitary cells in culture. Endocrinology. 1982;110(4):1147-1154.

53. van der Hoek J, Waaijers M, van Koetsveld PM, et al. Distinct functional properties of native somatostatin receptor subtype 5 compared with subtype 2 in the regulation of ACTH release by corticotroph tumor cells. Am J Physiol Endocrinol Metab. 2005;289(2):E278-E287.

54. Stalla GK, Brockmeier SJ, Renner U, et al. Octreotide exerts different effects in vivo and in vitro in Cushing's disease. Eur J Endocrinol. 1994;130(2):125-131.

55. Hofland LJ, van der Hoek J, Feelders R, et al. The multi-ligand somatostatin analogue SOM230 inhibits ACTH secretion by cultured human corticotroph adenomas via somatostatin receptor type 5. Eur J Endocrinol. 2005;152(4):645-654.

56. Batista DL, Zhang X, Gejman R, et al. The effects of SOM230 on cell proliferation and adrenocorticotropin secretion in human corticotroph pituitary adenomas. J Clin Endocrinol Metab. 2006;91(11):4482-4488.

57. Gola M, Bonadonna S, Mazziotti G, Amato G, Giustina A. Resistance to somatostatin analogs in acromegaly: an evolving concept? J Endocrinol Invest. 2006;29(1):86-93.

58. Amato G, Mazziotti G, Rotondi M, et al. Long-term effects of lanreotide SR and octreotide LAR on tumour shrinkage and GH hypersecretion in patients with previously untreated acromegaly. Clin Endocrinol (Oxf). 2002;56(1):65-71.

59. Melmed S, Colao A, Barkan A, et al; Acromegaly Consensus Group. Guidelines for acromegaly management: an update. J Clin Endocrinol Metab. 2009;94(5):1509-1517.
60. Ambrosi B, Bochicchio D, Ferrario R, Colombo P, Faglia G Screening tests for Cushing's syndrome. Clin Endocrinol (Oxf). 1990;33(6):809-811.

61. Invitti C, de Martin M, Brunani A, Piolini M, Cavagnini F. Treatment of Cushing's syndrome with the long-acting somatostatin analogue SMS 201-995 (sandostatin). Clin Endocrinol (Oxf). 1990;32(3): 275-281.

62. Lamberts SW, Uitterlinden P, Klijn JM. The effect of the longacting somatostatin analogue SMS 201-995 on ACTH secretion in Nelson's syndrome and Cushing's disease. Acta Endocrinol (Copenh). 1989;120(6):760-766

63. Tyrrell JB, Lorenzi M, Gerich JE, Forsham PH. Inhibition by somatostatin of ACTH secretion in Nelson's syndrome. J Clin Endocrinol Metab. 1975;40(6):1125-1127.

64. Petrini L, Gasperi M, Pilosu R, Marcello A, Martino E. Longterm treatment of Nelson's syndrome by octreotide: a case report J Endocrinol Invest. 1994;17(2):135-139.

65. Kelestimur F, Utas C, Ozbakir O, Selçuklu A, Kandemir O, Ozcan N. The effects of octreotide in a patient with Nelson's syndrome. Postgrad Med J. 1996;72(843):53-54.

66. Boscaro M, Ludlam WH, Atkinson B, et al. Treatment of pituitarydependent Cushing's disease with the multireceptor ligand somatostatin analog pasireotide (SOM230): a multicenter, phase II trial. $J$ Clin Endocrinol Metab. 2009;94(1):115-122.

67. Mazziotti G, Floriani I, Bonadonna S, Torri V, Chanson P, Giustina A. Effects of somatostatin analogs on glucose homeostasis: a metaanalysis of acromegaly studies. J Clin Endocrinol Metab. 2009; 94(5):1500-1508.

68. Giustina A, Veldhuis JD. Pathophysiology of the neuroregulation of growth hormone secretion in experimental animals and the human. Endocr Rev. 1998;19(6):717-797.

69. Giustina A, Wehrenberg WB. The role of glucocorticoids in the regulation of growth hormone secretion: mechanisms and clinical significance. Trends Endocrinol Metab. 1992;3(8):306-311.

70. de Bruin C, Feelders RA, Lamberts SW, Hofland LJ. Somatostatin and dopamine receptors as targets for medical treatment of Cushing's Syndrome. Rev Endocr Metab Disord. 2009;10(2):91-102.

71. Saiardi A, Borrelli E. Absence of dopaminergic control on melanotrophs leads to Cushing's-like syndrome in mice. Mol Endocrinol. 1998; 12(8):1133-1139

72. Croughs RJ, Koppeschaar HP, van't Verlaat JW, McNicol AM. Bromocriptine-responsive Cushing's disease associated with anterior pituitary corticotroph hyperplasia or normal pituitary gland. $J$ Clin Endocrinol Metab. 1989;68(2):495-498.

73. Lamberts SW, de Lange SA, Stefanko SZ. Adrenocorticotropin-secreting pituitary adenomas originate from the anterior or the intermediate lobe in Cushing's disease: differences in the regulation of hormone secretion. J Clin Endocrinol Metab. 1982;54(2):286-291.

74. Pivonello R, Ferone D, de Herder WW, et al. Dopamine receptor expression and function in corticotroph pituitary tumors. $J$ Clin Endocrinol Metab. 2004;89(5):2452-2462.

75. Illouz F, Dubois-Ginouves S, Laboureau S, Rohmer V, Rodien P. Use of cabergoline in persisting Cushing's disease. Ann Endocrinol (Paris). 2006;67(4):353-356.

76. Miyoshi T, Otsuka F, Takeda M, et al. Effect of cabergoline treatment on Cushing's disease caused by aberrant adrenocorticotropin-secreting macroadenoma. J Endocrinol Invest. 2004;27(11):1055-1059.

77. Pivonello R, de Martino MC, Cappabianca P, et al. The medical treatment of Cushing's disease: effectiveness of chronic treatment with the dopamine agonist cabergoline inpatients unsuccessfully treated by surgery. J Clin Endocrinol Metab. 2009;94(1):223-230.

78. Zanettini R, Antonini A, Gatto G, Gentile R, Tesei S, Pezzoli G. Valvular heart disease and the use of dopamine agonists for Parkinson's disease. N Engl J Med. 2007;356(1):39-46.

79. Feelders RA, de Bruin C, Pereira AM, et al. Pasireotide alone or with cabergoline and ketoconazole in Cushing's disease. $N$ Engl J Med. 2010;362(19):1846-1848. 
80. Heaney AP, Fernando M, Yong WH, Melmed S. Functional PPARgamma receptor is a novel therapeutic target for ACTH-secreting pituitary adenomas. Nat Med. 2002;8(11):1281-1287.

81. Giraldi FP, Scaroni C, Arvat E, et al. Effect of protracted treatment with rosiglitazone, a PPARgamma agonist, in patients with Cushing's disease. Clin Endocrinol (Oxf). 2006;64:219-224.

82. Ambrosi B, Dall'Asta C, Cannavo S, et al. Effects of chronic administration of PPAR-gamma ligand rosiglitazone in Cushing's disease. Eur J Endocrinol. 2004;151:173-178.

83. Suri D, Weiss RE. Effect of pioglitazone on adrenocorticotropic hormone and cortisol secretion in Cushing's disease. J Clin Endocrinol Metab. 2005;90:1340-1346.

84. Mancini T, Mazziotti G, Doga M, et al. Vertebral fractures in males with type 2 diabetes treated with rosiglitazone. Bone. 2009;45(4):784-788

85. Labeur M, Paez-Pereda M, Arzt E, Stalla GK. Potential of retinoic acid derivatives for the treatment of corticotroph pituitary adenomas. Rev Endocr Metab Disord. 2009;10(2):103-109.

86. de Marinis L, Bianchi A, Fusco A, et al. Long-term effects of the combination of pegvisomant with somatostatin analogs (SSA) on glucose homeostasis in non-diabetic patients with active acromegaly partially resistant to SSA. Pituitary. 2007;10(3):227-232.

87. Castinetti F, Fassnacht M, Johanssen S, et al. Merits and pitfalls of mifepristone in Cushing's syndrome. Eur J Endocrinol. 2009; 160(6):1003-1010.

88. Fallo F, Paoletta A, Tona F, Boscaro M, Sonino N. Response of hypertension to conventional antihypertensive treatment and/or steroidogenesis inhibitors in Cushing's syndrome. J Intern Med. 1993;234(6):595-598.

89. Fallo F, Sonino N, Barzon L, et al. Effect of surgical treatment on hypertension in Cushing's syndrome. Am J Hypertens. 1996;9(1):77-80.

90. Biering H, Knappe G, Gerl H, Lochs H. Prevalence of diabetes in acromegaly and Cushing syndrome. Acta Med Austriaca. 2000; 27(1):27-31.

91. Manelli F, Giustina A. Glucocorticoid-induced osteoporosis. Trends Endocrinol Metab. 2000;11:79-85.

92. Hermus AR, Smals AG, Swinkels LM, et al. Bone mineral density and bone turnover before and after surgical cure of Cushing's syndrome. J Clin Endocrinol Metab. 1995;80:2859-2865.

93. Manning PJ, Evans MC, Reid IR. Normal bone mineral density following cure of Cushing's syndrome. Clin Endocrinol (Oxf). 1992;36:229-234.

94. di Somma C, Pivonello R, Loche S, et al. Effect of 2 years of cortisol normalization on the impaired bone mass and turnover in adolescent and adult patients with Cushing's disease: a prospective study. Clin Endocrinol (Oxf). 2003;58:302-308.

95. Canalis E, Giustina A. Glucocorticoid-induced osteoporosis: summary of a workshop. J Clin Endocrinol Metab. 2001;86(12):5681-5685.

96. Canalis E, Bilezikian JP, Angeli A, Giustina A. Perspectives on glucocorticoid-induced osteoporosis. Bone. 2004;34(4):593-598.

97. Luisetto G, Zangari M, Camozzi V, Boscaro M, Sonino N, Fallo F. Recovery of bone mineral density after surgical cure, but not by ketoconazole treatment, in Cushing's syndrome. Osteoporos Int. 2001; 12:956-960.

98. di Somma C, Colao A, Pivonello R, et al. Effectiveness of chronic treatment with alendronate in the osteoporosis of Cushing's disease. Clin Endocrinol (Oxf). 1998;48:655-662.

99. Canalis E, Giustina A, Bilezikian JP. Mechanisms of anabolic therapies for osteoporosis. N Engl J Med. 2007;357(9):905-916.

Therapeutics and Clinical Risk Management

\section{Publish your work in this journal}

Therapeutics and Clinical Risk Management is an international, peerreviewed journal of clinical therapeutics and risk management, focusing on concise rapid reporting of clinical studies in all therapeutic areas, outcomes, safety, and programs for the effective, safe, and sustained use of medicines. This journal is indexed on PubMed Central, CAS,
100. Mazziotti G, Bianchi A, Bonadonna S, et al. Increased prevalence of radiological spinal deformities in adult patients with GH deficiency: influence of GH replacement therapy. J Bone Miner Res. 2006; 21(4):520-528.

101. Lane NE, Sanchez S, Modin GW, Genant HK, Pierini E, Arnaud CD. Bone mass continues to increase at the hip after parathyroid hormone treatment is discontinued in glucocorticoid-induced osteoporosis: results of a randomized controlled clinical trial. J Bone Miner Res. 2000;15:944-951.

102. Manelli F, Carpinteri R, Bossoni S, et al. Growth hormone in glucocorticoid-induced osteoporosis. Front Horm Res. 2002;30:174-183.

103. Giustina A, Bussi AR, Jacobello C, Wehrenberg WB. Effects of recombinant human growth hormone $(\mathrm{GH})$ on bone and intermediary metabolism in patients receiving chronic glucocorticoid treatment with suppressed endogenous GH response to GH-releasing hormone. J Clin Endocrinol Metab. 1995;80(1):122-129.

104. Angeli A, Guglielmi G, Dovio A, et al. High prevalence of asymptomatic vertebral fractures in post-menopausal women receiving chronic glucocorticoid therapy: a cross-sectional outpatient study. Bone. 2006; 39(2):253-259.

105. Terzolo M, Bossoni S, Alí A, et al. Growth hormone (GH) responses to GH-releasing hormone alone or combined with arginine in patients with adrenal incidentaloma: evidence for enhanced somatostatinergic tone. J Clin Endocrinol Metab. 2000;85(3):1310-1315.

106. Giustina A, Barkan A, Chanson P, et al; Pituitary Society; European Neuroendocrine Association. Guidelines for the treatment of growth hormone excess and growth hormone deficiency in adults. J Endocrinol Invest. 2008;31(9):820-838.

107. Veldman RG, Frölich M, Pincus SM, Veldhuis JD, Roelfsema F. Apparently complete restoration of normal daily adrenocorticotropin, cortisol, growth hormone, and prolactin secretory dynamics in adults with Cushing's disease after clinically successful transsphenoidal adenomectomy. J Clin Endocrinol Metab. 2000;85(11):4039-4046.

108. Degerblad M, Brismar K, Rähn T, Thorén M. The hypothalamuspituitary function after pituitary stereotactic radiosurgery: evaluation of growth hormone deficiency. J Intern Med. 2003;253(4): 454-462.

109. Pecori Giraldi F, Andrioli M, de Marinis L, et al. Significant GH deficiency after long-term cure by surgery in adult patients with Cushing's disease. Eur J Endocrinol. 2007;156(2):233-239.

110. Höybye C, Ragnarsson O, Jönsson PJ, et al. Clinical features of GH deficiency and effects of 3 years of GH replacement in adults with controlled Cushing's disease. Eur J Endocrinol. 2010;162(4):677-684.

111. Doga M, Bonadonna S, Gola M, Mazziotti G, Giustina A. Growth hormone deficiency in the adult. Pituitary. 2006;9(4):305-311.

112. Doga M, Bonadonna S, Gola M, et al. Current guidelines for adult GH replacement. Rev Endocr Metab Disord. 2005;6(1):63-70.

113. Colson A, Brooke AM, Walker D, et al. Growth hormone deficiency and replacement in patients with treated Cushing's Disease, prolactinomas and non-functioning pituitary adenomas: effects on body composition, glucose metabolism, lipid status and bone mineral density. Horm Res. 2006;66(6):257-267.

114. Webb SM, Mo D, Lamberts SW, et al; International HypoCCS Advisory Board. Metabolic, cardiovascular, and cerebrovascular outcomes in growth hormone-deficient subjects with previous Cushing's disease or non-functioning pituitary adenoma. J Clin Endocrinol Metab. 2010;95(2):630-638.

\section{Dovepress}

EMBase, Scopus and the Elsevier Bibliographic databases. The manuscript management system is completely online and includes a very quick and fair peer-review system, which is all easy to use. Visit http://www.dovepress.com/testimonials.php to read real quotes from published authors. 